\title{
COVID-19: fenomenología del miedo y hermenéutica de la solidaridad en la peste de Atenas y en la pandemia contemporánea*
}

Recibido: 13/03/2021 | Revisado: 13/08/2021 | Aceptado: 10/09/2021

DOI: 10.17230/co-herencia.18.35.12

\section{Germán Darío Vélez López** \\ gdvelez@eafit.edu.co}

\begin{abstract}
Resumen El propósito central de este artículo consiste en realizar un análisis de la pandemia actual, intentando situar estratos básicos del fenómeno, y particularmente el modo como se estructura su mundo y los vínculos de coexistencia entre los individuos, tomando como hilo conductor un elemento que la analítica existencial heideggeriana destaca como característico del modo de apertura del hombre al mundo: el temple anímico o la disposición afectiva. Para situar este elemento y buscar una orientación para nuestra indagación, analizaremos el relato de Tucídides acerca de la peste que asoló a Atenas a finales del siglo $v$ a. C. Partiendo de las indicaciones que extraeremos de Tucídides nos encaminaremos hacia el campo de la analítica existencial para descubrir a partir de su enfoque el modo como se definen las relaciones mundanas en conexión con el temple anímico del miedo. Nos interesa mostrar cómo este temple anímico motiva una especial transformación del sentido del virus responsable de la pandemia actual, transformación que nos lleva a considerar su carácter mutualista (y no solo parasitario), lo cual remitirá en última instancia y de manera retroactiva a una mejor determinación del modo de ser de la existencia humana, como esencialmente vinculada al otro, como co-existencia.
\end{abstract}

\section{Palabras clave:}

Fenomenología, Grecia clásica, miedo, pandemia, peste, temple anímico, virus.

\section{COVID-19: Phenomenology of fear and hermeneutics of solidarity in the plague of Athens and in the contemporary pandemic}

\footnotetext{
Abstract The main purpose of this article is to conduct an analysis of the current pandemic, attempting to locate basic layers of the phenomenon, in particular, the way its world is structured and the links of coexistence between individuals,
}

Artículo de reflexión adscrito al proyecto de investigación "Tiempo, ser y movimiento" (Código 828000072), financiado por la Vicerrectoría de Descubrimiento y Creación de la Universidad EAFIT.

* Doctor en Filosofía Contemporánea. Profesor titular del Departamento de Humanidades de la Universidad EAFIT, Medellín-Colombia. ORCID: 0000-00027911-9260 
taking as thread an element that analytics Heideggerian existentialism highlights as characteristic of man's way of opening to the world: the emotional temper or affective disposition. To place this element and guide our questions, we will analyze Thucydides' account of the plague that devastated Athens at the end of the fifth century BC. Starting with Thucydides' indications, we will move toward the field of existential analytics to discover how worldly relations are defined in connection with the world from his approach. We are interested in showing how this emotional temper motivates a special transformation of the meaning of the virus responsible for the current pandemic, a transformation that leads us to consider its mutual (and not only parasitic) nature, which will ultimately and retroactively refer to a better determination of the human existence, as essentially linked to the other, as coexistence.

\section{Keywords:}

Phenomenology, Classical Greece, fear, pandemic, plague, mood, virus.

\section{La peste de Atenas: desánimo, desespero y miedo}

Por el terrible cansancio estaban exhaustos todos sus miembros, y la pena embargaba su ánimo observando a los troyanos, que el enorme muro en tropel traspasaron (Il. XIII,85-87)

El canto XIII de la llíada se abre con un episodio de profunda pena para los soldados de Agamenón: los troyanos penetran el muro construido por los aqueos como línea de defensa entre ellos y sus naves. La visión de los troyanos traspasando el muro embarga el ánimo de los aqueos, llenándolo de pena. Dicho de modo griego,

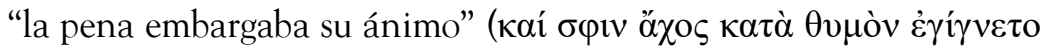

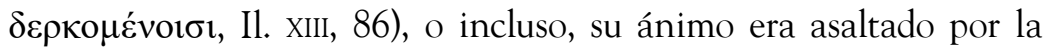
pena, así como las murallas por su enemigo. Sus murallas y su cuerpo no resisten, el terrible cansancio y la débil defensa de las murallas, o la intervención fortuita de un dios, parecen augurarle a los aqueos una ruina en tierra extranjera. Este momento dramático del sitio de Troya no deja de resonar en las palabras de Tucídides, quien relata, siglos más tarde, el profundo desánimo que embarga a los atenienses cuando les llega la peste. Pero hay un motivo adicional que nos inclina a elegir este pasaje de la Ilíada y ponerlo en relación con la 
narración de Tucídides: en ambos textos se nombra el presentarse o el suceder de algo que embarga con pesadumbre, enfermedad y muerte la vida de los atenienses.

A los aqueos los embarga la pena; Tucídides, por su parte, se ocupará de contar cómo la enfermedad se presentaba y a reconocerla por sus signos, de modo que si llega a presentarse de nuevo, esté el pueblo advertido y no lo sorprenda otra vez lo desconocido. La enfermedad ingresa en Atenas como los troyanos que rompen la muralla de los griegos. Los invadidos se convierten en invasores, y los conquistadores en conquistados. Pero en esta situación el historiador tiene la palabra de su lado: "Yo, por mi parte, describiré cómo se

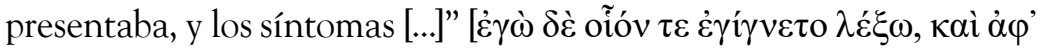
$\tilde{\omega} v \ddot{\alpha} v \tau \imath \varsigma \sigma \kappa о \pi \tilde{\omega} v]$ (Th. Hist. II, 48, 3). ${ }^{1}$

Esta descripción es el acto correlativo de la irrupción de una enfermedad, que por presentarse por primera vez $z^{2}$ es como el arquetipo del presentarse mismo. Con respecto a esta enfermedad, la palabra de Tucídides, en una época en la que las disciplinas aún no se habían especializado y escindido, podría reclamar no solo el título de "historia", sino también el de "fenomenología". Tanto más cuanto que, como lo haría un fenomenólogo, ha renunciado al desciframiento metafísico: génesis y causalidad están por fuera de su alcance, están, por decirlo así, entre paréntesis; que otros, sabios o ignorantes, se dediquen a dar su opinión sobre tales cosas. La tarea del historiador-fenomenólogo es más modesta y urgente. Uno podría sentirse tentado a sustituir "presentarse" por "aparecer" y sellar con ello el carácter estrictamente fenomenológico de la aproximación del historiador, pero el término no es de la familia "phainomena"; en su lugar tenemos que el término clave, tanto en los versos de Homero

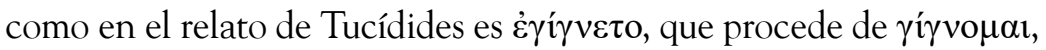
palabra abstracta que significaba llegar a ser, devenir, pero que, según el contexto, podía significar "nacer", "ser producido", "tener lugar", "suceder", "ocurrir". De un modo incluso más modesto, encontramos

Jaquelline de Romilly traduce del mismo modo: "Pour moi, je dirai comment cette maladie se présentait; les signes à observer" (1973, p. 35).

2 "Nada podían hacer los médicos por su desconocimiento de la enfermedad que trataban por primera vez" (Th. Hist. II, 47, 4). 
que "ta gignomena" podría significar simplemente "los hechos". A pesar de esta restricción impuesta por el léxico, procedamos a examinar el modo como Tucídides se ocupó de semejante descripción de manera tal que podamos apreciar la raigambre fenomenológica de su empresa.

En primer lugar, no dejaremos de insistir en el carácter particular del observador que renuncia a dar una opinión acerca de cosas que caen por fuera de su experiencia. Tucídides se pronuncia acerca de lo que él mismo vio o padeció, dejando a otros, conocedores o no, que se expresen sobre las posibles causas y la procedencia de la enfermedad. Para Tucídides, su palabra está ligada indisolublemente a su experiencia posible y, por lo tanto, al modo como la enfermedad se presentaba ante él:

Sobre esta epidemia, cada persona, tanto si es médico como si es profano, podrá exponer, sin duda, cuál fue, en su opinión, su origen probable así como las causas de tan gran cambio que, a su entender, tuvieron fuerza suficiente para provocar aquel proceso. Yo, por mi parte, describiré cómo se presentaba; y los síntomas con cuya observación, en el caso de que un día sobreviniera de nuevo, se estaría en las mejores condiciones para no errar en el diagnóstico, al saber algo de antemano, también voy a mostrarlos, porque yo mismo padecí la enfermedad y vi personalmente a otros que la sufrían (Th. Hist. II, 48, 3).

Esta posición del observador que reclama el derecho a la palabra desde la experiencia en primera persona, tanto por haber visto como por haber padecido él mismo, en su cuerpo, la enfermedad, es la primera condición de la aproximación fenomenológica. Pero siendo una condición necesaria, no es suficiente. Se requiere, además, que el observador renuncie a pronunciarse acerca de tesis trascendentes, como serían aquellas referidas a la procedencia o a las causas de la enfermedad. En estricta inmanencia, el observador no puede y no debe ceder a la tentación de dar su opinión acerca de tales asuntos que exceden su experiencia.

Una vez instalado en este campo fenomenal estricto puede avanzar Tucídides con la descripción de los síntomas de la enfermedad, la cual conduce la mayoría de las veces a la muerte del enfermo. La enfermedad es descrita, en primer lugar, en su foco de 
acción: el cuerpo humano. Después de mostrar en detalle los efectos de la enfermedad en la cabeza, la garganta, el pecho y el estómago, concluye Tucídides esta descripción con una síntesis general:

El mal, después de haberse instalado primero en la cabeza, comenzando por arriba recorría todo el cuerpo, y si uno sobrevivía a sus acometidas más duras, el ataque a las extremidades era la señal que dejaba: afectaba, en efecto, a los órganos genitales y a los extremos de las manos y de los pies; y muchos se salvaban con la pérdida de estas partes, y algunos incluso perdiendo los ojos. Otros, en fin, en el momento de restablecerse, fueron víctimas de una amnesia total y no sabían quiénes eran ellos mismos ni reconocían a sus allegados (Th. Hist. II, 49, 7).

Antonio Hermosa le da el sonoro apelativo de "imperialismo somático" a este modo de despliegue de la enfermedad:

La peste se caracterizaba asimismo por su imperialismo somático. Entraba por la cabeza, mas una vez allí aferraba la ocasión iniciando un proceso de expansión incontrolable hasta los miembros inferiores, cuya sola limitación conocida era la muerte de la víctima antes de que la enfermedad tocase fondo (Hermosa Andújar, 2016, p. 118).

Así, pues, una vez descrito este proceso de expansión imperialista de la enfermedad en el cuerpo, quizás a partir de la experiencia más inmediata, pues Tucídides se contagió y sobrevivió a la peste, nos relata el historiador lo que ocurría en el ámbito de lo que podríamos denominar el mundo compartido, en el sentido del círculo de los más allegados al enfermo:

Pero lo más terrible de toda la enfermedad era el desánimo que se apoderaba de uno cuando se daba cuenta de que había contraído el mal (porque entregando al punto su espíritu a la desesperación, se abandonaban por completo sin intentar resistir), y también el hecho de que morían como ovejas al contagiarse debido a los cuidados de los unos hacia los otros: esto era sin duda lo que provocaba mayor mortandad. Porque si, por miedo, no querían visitarse los unos a los otros, morían abandonados, y muchas casas quedaban vacías por falta de alguien dispuesto a prestar sus cuidados; pero si se visitaban, perecían, sobre todo quienes de algún modo hacían gala de generosidad, pues, movidos por su sentido del honor no tenían ningún cuidado de sí mismos entrando en casa de sus amigos cuando, al final, a los mismos familiares, vencidos por la magnitud del mal, ya no les quedaban fuerzas ni para llorar a los que se iban. No obstante, eran los que ya habían salido de la enfermedad quienes más se compadecían de los moribundos 
y de los que luchaban con el mal por conocerlo por propia experiencia y hallarse ya ellos en seguridad; la enfermedad, en efecto, no atacaba por segunda vez a la misma persona, al menos hasta el punto de resultar mortal (Th. Hist. II, 51, 4-6).

Una vez descrito el efecto de la enfermedad sobre el cuerpo, en esa especie de efecto axial e imperialista, que desciende desde la cabeza hasta las extremidades, y antes de dar paso a la fenomenología de la enfermedad en el mundo compartido más amplio de la polis, nos ofrece Tucídides estas breves pero precisas indicaciones acerca del estado de ánimo o del temple anímico del enfermo. Inicia este segmento de la descripción contándonos qué consideraba entre todo "lo más terrible" (to deinótaton) de la enfermedad. Lo más terrible era algo que no concernía, estrictamente hablando, al orden somático o del cuerpo, sino a ese orden liminar del ánimo. Allí lo más terrible era el desánimo, la athymía que se apoderaba del enfermo, quien perdía la esperanza, cayendo en el desespero (anélpistos). Esta modificación profunda del temple anímico tendrá repercusiones también terribles, no solamente sobre la vida del enfermo, sino ante todo sobre la vida de la polis, tal como nos lo propondrá un poco más adelante el historiador ateniense.

Pero antes de referirse a la vida compartida en la polis, a la vida que podríamos denominar pública, se refiere Tucídides, como en una especie de gradación del ámbito del mundo de la vida, a los vínculos de sangre y de amistad entre los enfermos. En efecto, cuando la enfermedad y la muerte se ensañaban con una familia, al punto de que ni los sobrevivientes tenían ya presencia de espíritu para acompañar a sus moribundos, eran los amigos quienes entraban a sus casas. Ocurría entonces que estos, al hacer gala de generosidad, se exponían al contagio, enfermaban y morían. La enfermedad, en cierto modo, se servía del sentimiento de amistad y generosidad para expandir su contagio más allá del cerco inmediato de los habitantes de una misma casa. El efecto que no producía por contacto inmediato entre miembros de una familia lo alcanzaba la peste extendiendo su influencia a los lazos de amistad y a los sentimientos de generosidad. Cobraba entonces la peste, por partida doble, a familiares y amigos, diezmando el mundo compartido inmediato de los habitantes de Atenas. 
Una vez que el ataque de la peste había mostrado sus más terribles efectos, el desánimo y la desesperación se proyectaban a la vida de la polis, donde adquirían un rostro diferente y siniestro a la vez:

También en otros aspectos la epidemia acarreó a la ciudad una mayor inmoralidad. La gente se atrevía más fácilmente a acciones con las que antes se complacía ocultamente, puesto que veían el rápido giro de los cambios de fortuna de quienes eran ricos y morían súbitamente, y de quienes antes no poseían nada y de repente se hacían con los bienes de aquéllos. Así aspiraban al provecho pronto y placentero, pensando que sus vidas y sus riquezas eran igualmente efímeras. Y nadie estaba dispuesto a sufrir penalidades por un fin considerado noble, puesto que no tenía la seguridad de no perecer antes de alcanzarlo. Lo que resultaba agradable de inmediato y lo que de cualquier modo contribuía a ello, esto fue lo que pasó a ser noble y útil. Ningún temor de los dioses ni ley humana los detenía; de una parte juzgaban que daba lo mismo honrar o no honrar a los dioses, dado que veían que todo el mundo moría igualmente, y, en cuanto a sus culpas, nadie esperaba vivir hasta el momento de celebrarse el juicio y recibir su merecido; pendía sobre sus cabezas una condena mucho más grave que ya había sido pronunciada, y antes de que les cayera encima era natural que disfrutaran un poco de la vida (Th. Hist. II, 53, 1-4).

La inmoralidad (àvouías) de la polis es presentada por Tucídides como un efecto directo de los cambios súbitos de

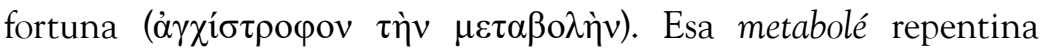

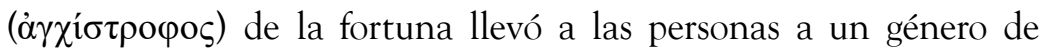
acción ruinosa: realizar más fácilmente acciones con las que antes

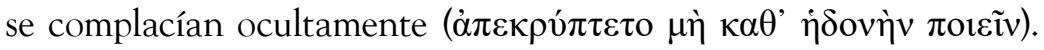
Hay una especie de cambio repentino en el régimen de realización de ciertas acciones tendientes al placer. Tucídides no nos dice que de repente las personas se entregaran a un tipo enteramente nuevo de acciones o que descubrieron nuevos placeres, sino que acciones que antes realizaban, o aún más, en las que se complacían (hedoné) de manera oculta, hipócrita ( $\alpha \pi$ $о$ v́ $\pi \tau \omega)$, ahora las realizan más fácilmente. Por esta razón, la gente comienza a buscar el "provecho

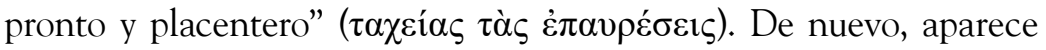
una especie de aceleración, con efectos nefastos para la moral pública. Esto resulta muy llamativo desde el punto de vista de la fenomenología de la ruina moral que sobreviene con la peste. En 
primer lugar, menciona Tucídides el cambio repentino de fortuna,

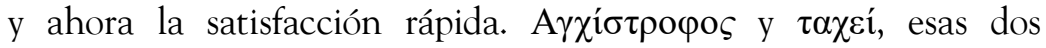
modificaciones del ritmo, o esas dos aceleraciones parecen ser, si no la causa, por lo menos el síntoma más evidente de una modificación profunda en la moral que hace que, a partir de ese momento, "nadie

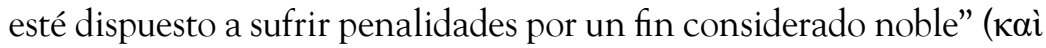
$\tau$ con lo cual nos lega Tucídides, adicionalmente, aunque sea en una fórmula negativa, una precisa definición de la moral pública.

Podemos afirmar, en consecuencia, que lo que resulta comprometido en grado sumo es la perseverancia $(\pi \rho 0 \sigma \tau \alpha \lambda \alpha \imath \pi \omega \rho \varepsilon \tilde{\imath})$ en aquello que es considerado o tenido por noble o bello (kalós). Ahora, lo más notable, podríamos decir, es que se produce en ese instante -y merced a esta aceleración que hemos mencionado- una lesión en la moral o, incluso de modo más radical, una verdadera transmutación de valores: lo que antes se conseguía con perseverancia y esfuerzo dejó de ser tenido por noble y bello y su lugar lo ocupó lo inmediatamente agradable. Esta inversión de la moral acarreó, a su vez, una corrupción del respeto a las leyes divinas y humanas. Pero este drama de la descomposición moral lo presenta Tucídides con neutralidad, por no decir con indulgencia, tal como lo deja en parte traslucir la última frase en la que nos dice que, teniendo los atenienses la vida sentenciada a muerte por la enfermedad, "era natural que disfrutaran un poco de la vida". Cierra pues Tucídides esta descripción de los efectos de la peste sobre el mundo compartido mostrando la transformación moral y la transmutación de los valores, en donde resulta comprometido el sentido de lo bello y noble. Pero el historiador-fenomenólogo, quizás queriendo mantener la neutralidad de su relato, después de referir los desmanes en los que incurren los atenienses acosados por la enfermedad, en una frase restablece el equilibrio entre el sacrificio que se aproxima ( $\sigma \varphi \tilde{\omega} v \dot{\varepsilon} \pi 1 \kappa \rho \varepsilon \mu \alpha \sigma \theta \tilde{\eta} v \alpha \imath)$ y el razonable o apenas normal (घikòs) disfrute postrero de la vida

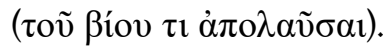

Pero visto en detalle, en medio de lo que es juzgado como normal o razonable, se nos muestra algo que no parece ajustarse a una medida: el miedo. Examinemos, pues, una vez más, qué pasa 
con el miedo. Este afecto se asoma en "lo deinótaton", "lo más terrible" o, como también podría traducirse, "lo más pavoroso" de la enfermedad: es pavorosa entre todas las cosas una transformación del ánimo que acarrea la enfermedad, la athymía, el profundo desánimo que embargaba a quienes la contraían. El desánimo, a su vez, se da como una especie de reacción o como una expresión concomitante de la ausencia de esperanza, la desesperación. Esa pavorosa athymíaanélpistos repercute en el mundo de la vida compartida, tanto en el orden de los allegados (familiares y amigos) como en el de la vida pública en general modulando, por decirlo así, la intensidad del miedo. En dos ocasiones lo menciona Tucídides y empleando dos términos diferentes. En la primera, el miedo (dediótes) es el sentimiento que embarga a familiares que abandonaban la casa y al enfermo para evitar el contagio, y en la segunda, no alcanzando phóbos a obligar a los hombres a honrar a los dioses (por ejemplo, cumpliendo cabalmente con los rituales de entierro). El miedo aparece, pues, por partida doble en el relato de Tucídides: (1) "Porque

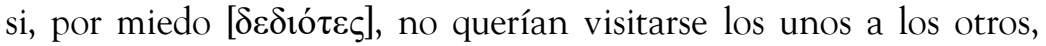

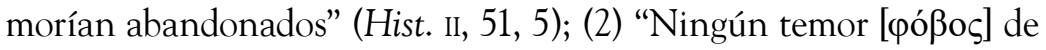
los dioses ni ley humana los detenía" (Hist. II, 53, 4). ${ }^{3}$

En el primer caso, era tan intenso que empujaba a las personas a alejarse de los enfermos y a abandonar su casa y su familia, y, en el segundo, no era tanto como para obligarlos a observar los preceptos divinos. El miedo parece pecar por exceso en el primer caso y por defecto en el segundo. Produce pánico entre los primeros, e impiedad entre los segundos. Podríamos resumir esta situación referente al miedo diciendo que en la peste el afecto no consigue

\footnotetext{
3 El primer término empleado por Tucídides para referirse al miedo dediótes pertenece a la familia deido, ampliamente usada por Homero para referirse al miedo, como lo muestra de manera detallada el estudio de Zaborowski (2002, p. 71 y ss.). Siguiendo a Zaborowski, constatamos que el término dediótes es usado con mayor frecuencia en Homero que el mismo phóbos, palabra con la cual será designado el miedo por el Estagirita en su Retórica. Ahora bien, como anota Simpson (2019), el conjunto de términos relativos al miedo es amplio en Homero, y por extensión, podríamos decir que lo es en el mundo griego antiguo en la época de Tucídides, pudiendo traslaparse en su uso: "The fear-terror word cluster in Homer is especially rich and diverse and includes a host of other terms besides deimos, deos, deinos, and phobos. Emotion words are hard to distinguish one from another: their very logic may well be that they overlap" (2019, p. 52).
} 
ocupar su justo medio. Sabemos que al proponer una fórmula como esta pisamos un terreno en cierto modo ajeno, por ser el de la ética, por demás aún inexistente, al menos bajo la forma "sistemática" en que aparecerá un siglo después con el tratado de Aristóteles. Con todo, nos aventuramos a seguir esta vía empujados por la descripción de Tucídides. Siguiendo esta línea de interpretación diremos que la peste descentra al afecto del miedo y aunque parece suscitarlo, parece también llevarlo hasta los límites de su eficacia, pues, como dirá Aristóteles en la Retórica:

[Para sentir miedo] es, más bien, preciso que aún se tenga alguna esperanza de salvación por la que luchar. Y un signo de ello es que el temor hace

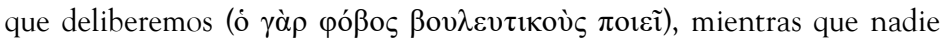
delibera sobre cosas desesperadas (Rh., 1383a5).

Esta idea, expresada en último término, ya la había planteado al comienzo de la Retórica, y de un modo que reenvía directamente a desarrollos más amplios de la cuestión en la Ética Nicomáquea: ${ }^{4}$

De cualquier forma, deliberamos sobre lo que parece que puede resolverse de dos modos, ya que nadie da consejos sobre lo que él mismo considera que es imposible que haya sido o vaya a ser o sea de un modo diferente, pues nada cabe hacer en esos casos (Rh., 1357a4).

Una vez situado de esta manera el afecto, en su lugar propio o medio, así como en las posiciones extremas, en la tensión a la cual lo somete la situación en la que se desenvuelve durante la peste en Atenas, pasemos a considerar la situación actual de pandemia producida por el virus de la COVID-19, tomando como hilo conductor este temple anímico característico de la peste. Para situarnos en un contexto de reflexión históricamente más próximo, partiremos del esclarecimiento del temple anímico que realiza Heidegger a partir de su "ontologización" de la Retórica de Aristóteles, exposición que encontramos en el $\$ 30$ de Ser y tiempo (1998, pp. 164-166).

4 Véase a este respecto la Ética Nicomáquea III 3, 1112 $\mathrm{a}_{30}-1113 \mathrm{a}_{2}$, y vi 2, 1139 $\mathrm{b}_{7-9}$. 


\section{El miedo ante la covID-19: parasitismo y mutualismo}

\section{Fenomenología del miedo}

Que el miedo ante el contagio sea un temple anímico generalizado y dominante de la época actual, creo que es algo que no admite mayor discusión, no solamente por comparación, por así decirlo, con la fenomenología de la peste en Atenas, sino por su modo propio de presentarse en el mundo contemporáneo. La situación mundial actual produce miedo y se trata de un miedo bien determinado. No digo con esto que el miedo sea el único temple anímico actual, ni que además de un miedo bien determinado puedan existir formas oscuras, confusas del miedo. Pero algo que la situación actual de pandemia localiza bien es una fuente global y omnipresente del miedo: el virus. El SARs-Cov-2, responsable de la COVID-19, constituye lo temible mismo, o el "ante que" del miedo en la situación de pandemia. Pero ¿qué es el SARs-Cov-2 ante el que tenemos miedo?

Podríamos responder: es un virus, es decir, una entidad para la cual no tenemos hoy un consenso acerca de sus características biológicas básicas: ¿es un ser vivo?, ¿es un organismo? Las características ónticas del virus son tan poco evidentes que pareciera que aún tuviéramos que seguir repitiendo la definición tautológica propuesta hace medio siglo por el premio nobel de Biología André Lwoff: "[U]n virus es un virus" (1957, p. 240). Esta definición hace en cierto modo más ominosa la omnipresencia del virus pues, remitido a sí mismo, parece oponer una férrea resistencia a la dialéctica, y esto por no hablar aún siquiera de vacunas. Preguntemos, entonces, antes de preocuparnos por la dificultad de una determinación científica, por el modo de ser del virus. ¿Qué es, ontológicamente hablando, un virus? Un virus puede ser considerado como un objeto de laboratorio. El temple anímico que lo descubre de esta manera no es el miedo, sino más bien algo del orden de la curiosidad investigativa. Como tal objeto, presumiblemente el SARS-COV-2 estuvo confinado durante largo tiempo en un laboratorio chino. Pero ese virus no es el que da miedo actualmente. El virus temible es el que salió al mercado, a la calle, a las oficinas, a las casas, el virus-mundano, no el virus-objeto. Con respecto al virus, podemos decir que su sentido de ser depende del 
contexto en el que se lo considere, contexto abierto por el temple anímico que lo descubre en el mundo que habitamos o en el espacio cerrado del laboratorio. El virus que da miedo no tiene el modo de ser de un objeto, de algo que simplemente está ahí para la observación. Dicho de una forma existencial-analítica, no tiene el modo de ser de la presencia subsistente (Vorhandenheit), sino de la empleabilidad (Zuhandenheit).

En el mundo circundante abierto por el miedo, un virus, estrictamente hablando, nunca es, pues el virus solo es en la medida en que está en relación con un anfitrión. El miedo nos muestra al virus en su amenazante estar remitido a un anfitrión. El virus se nos muestra como parásito obligado en la mirada circunspectiva del miedo, incluso antes de que sepamos que biológicamente depende de la capacidad metabólica de una célula anfitrión para replicarse. La replicación y multiplicación de un virus exhibe una estructura altamente remisional, es decir, existe como estando remitido a otro, y en esto, más que como un objeto independiente, se comporta como vector perjudicial dentro de una totalidad respeccional o totalidad de relaciones de remisión (del tipo $a$ es para $b, b$ es para $c$, y así sucesivamente). En este sentido un virus no es un objeto, pero quizás sí es algo que en un sentido estructural está emparentado con las herramientas en la medida en que el ser de estas consiste en estar remitiendo siempre a otras, y que con otras herramientas hacen parte de una totalidad respeccional que desemboca en un ente que no se comporta como una herramienta, sino que es un ser humano en función del cual (de su proyecto vital) el conjunto de herramientas está estructurado.

Pero el SARS-Cov-2 no es algo que queramos tratar como una herramienta. Quisiéramos, por el contrario, vérnoslas con él como con un objeto: a distancia, aislado, confinado en un laboratorio. No obstante, lo propio del virus es justo su tendencia respeccional, la cual está escrita, literalmente, en su ADN. El virus, a pesar nuestro, se comporta como una herramienta en cuanto siempre y necesariamente remite a otra cosa que él, y configura en ese remitir una totalidad respeccional que nos amenaza. En sentido estricto, no es útil ni herramienta, pero se comporta como tal. Es nocivo para. El virus, en cuanto "parásito obligado" está necesariamente remitido a otro 
en quien despliega su potencial nocividad. La totalidad respeccional descubierta por el miedo nos muestra el mundo circundante como un mundo de superficies en potencia contaminadas por el virus, y dispuestas a contaminar otras superficies por contacto. En todos estos respectos de posible incidencia y presencia del virus nos las vemos con un todo de útiles contaminantes y contaminables $\mathrm{y}$, al mismo tiempo, merced al proyecto de cuidado de la vida, con un todo de útiles que se disponen como barrera frente al virus.

El mundo pandémico es un mundo articulado por una estructura de significatividad en la que se oponen dos significados básicos: los vectores perjudiciales contaminados y contaminantes y las respectivas barreras que intentan mantenerlos a distancia de nosotros. La prevalencia de estas dos direcciones de la significatividad muestra un particular empobrecimiento del sentido del mundo, que retroactivamente, por reflejo, empobrece o simplifica nuestro estar en el mundo. El empobrecimiento significativo del mundo que le da contenido a la vida simplifica la vida misma y la torna proclive a la pobreza esencial de sentido. El empobrecimiento significativo del mundo experimentado a partir del temple anímico del miedo tiene, con todo, un rendimiento ontológico positivo: nos muestra el mundo como capaz de acoger, de ser hospitalario, justamente a partir de la estructura del virus mismo, a partir de su heteronomía vital, es decir, de su parasitismo obligado. El mundo es el anfitrión en sentido eminente de todo ente que tiene el modo de ser del parasitismo obligado. Los virus son entidades que se han hospedado en el mundo desde el comienzo de la vida misma, mucho antes, incluso, de que se desarrollara la forma de vida humana. El mundo hospeda virus y también hospeda, mucho más recientemente, a seres humanos. El ser humano es también huésped del mundo. En qué medida sea el hombre, al mismo tiempo, un parásito obligado del mundo es una cuestión que actualmente nos planteamos, como pregunta ecológica. En Así habló Zaratustra hace Nietzsche la declaración nihilista según la cual el hombre es una enfermedad epidérmica de la tierra. Si este nihilismo se ha desplegado y ha suscitado transformaciones positivas del habitar la tierra es un asunto que no hemos resuelto aún y que hoy en día parece tener que responderse de manera negativa. Pero 
reflexionando a partir del temple anímico del miedo ante la pandemia de la COVID-19, y del peculiar empobrecimiento de la significatividad, de la particular suspensión de la autosuficiencia de la vida, nos es dado apreciar de un modo más patente el carácter, si no de parásito obligado, al menos de huésped obligado del hombre en el mundo. Existir es para nosotros, seres humanos, estar-en-en-el-mundo en el sentido de estar hospedados en el mundo.

\section{El SARS-Cov-2: del parasitismo al mutualismo}

Recientes estudios en biología buscan destacar frente al carácter parasitario de muchos virus la función mutualista de algunos de ellos, quizás no pocos de ellos. En "Mutualistic viruses and the heteronomy of life", el filósofo y diplomado en Inmunología Thomas Pradeu propone que

si bien los virus se han concebido comúnmente como dañinos, investigaciones recientes han demostrado que muchos de ellos son neutrales (no afectan la aptitud [fitness] del anfitrión) o incluso mutualistas (aumentan la aptitud del anfitrión) [...] El mutualismo no es una pregunta de sí / no, sino más bien una cuestión de grado, y además es a menudo una pregunta contextual (depende de las condiciones espaciales y temporales) [...] (Pradeu, 2016, p. 82). ${ }^{5}$

Pradeu centra su reflexión en un conjunto de virus que se muestran no solamente como benéficos sino "incluso como indispensables para el desarrollo, la supervivencia y la reproducción del anfitrión" (Pradeu, 2016, p. 82). Desde luego, el estudio de Pradeu no aplica directamente para el SARS-Cov-2. No obstante, al plantear la cuestión de grado y de contexto, abre un camino que podríamos explorar a partir del temple anímico del miedo. El primer paso consiste en reconocer el peso que ha tenido la denominación de la entidad temible en nuestra comprensión de esta. La palabra proviene del latín, y fue empleada de forma temprana por Celsus para designar un fluido venenoso. Virus en latín quiere decir "veneno" y es en tal condición que es descubierto por el temple del miedo. Sin embargo,

5 Las traducciones de las citas de los textos en inglés son de mi autoría. 
este temple anímico nos descubre el mundo, al mismo tiempo, en una particular circunscripción espacio-temporal en la que solo lo temible comparece. Ahora bien, si estuviéramos en capacidad de suspender el temple anímico del miedo, realizando una especie de epojé del miedo, nos encontraríamos templados de un modo diferente, y nuestra capacidad de apertura al mundo se modificaría también. La ciencia depende de este tipo de transformaciones, y de ellas depende también la filosofía. Adquirir un punto de vista científico consiste, en su sentido existencial, en permitir que un temple anímico se apodere de otro o cultivar esa posibilidad mediante una particular ejercitación. El miedo "reducido" en sentido fenomenológico puede corresponder a una curiosidad prudente. La prudente curiosidad ante el virus es aquello que le permite en primer lugar a la ciencia descubrir en este objeto un sentido paradójico, es decir, contrario a la opinión común. Después de todo, pueden existir también virus no patógenos, es decir, virus que no se comporten como parásitos obligados, sino como entidades mutualísticas, esto es, capaces de colaborar con el anfitrión incrementando sus aptitudes para la vida. Esta transformación del temple anímico conlleva dos modificaciones importantes, si atendemos a lo expresado por Pradeu (2016): suspender el régimen binario sí/no, útil/nocivo, y hacer ingresar el sentido de la acción del virus en un contexto más amplio que el contexto inmediato determinado por su remisión directa al anfitrión. Esta doble transformación no tiene que aplicarse solo a aquellos virus que hayan sido previamente reconocidos como mutualísticos, sino que es esa nueva posición alcanzada desde la transformación del temple anímico la que hace posible su descubrimiento.

¿Qué pasa, entonces, con el SARs-Cov-2 si lo sometemos a estas consideraciones? Quizás lo primero que salta a la vista es que, tratándose de la vida humana, la pregunta acerca de si un virus puede incrementar su aptitud no puede medirse exclusivamente en términos de la aptitud biológica de los anfitriones, y que la aptitud misma, en términos existenciales, excede el concepto básico de la biología. Por ejemplo, hablamos de sociedades enfermas, y no solo porque un gran número de individuos estén contagiados por un virus, sino porque reconocemos en la salud un criterio más amplio que el 
meramente biológico para calificar la relación de la sociedad con la vida. Una sociedad enferma es una sociedad que experimenta una reducción en sus aptitudes para vivir como sociedad, e inversamente una sociedad sana es una que experimenta un sostenimiento o incremento de esas aptitudes.

La vida en sociedad, la vida social es co-originaria con la vida en el mundo. Para el ser humano estar en el mundo es al mismo tiempo estar con otros hombres, y los vínculos con su mundo compartido no son menos vitales que los vínculos con su mundo circundante. Podríamos decir, siguiendo la terminología de Heidegger, que si la solicitud o el velar-por (Fürsorge) es el título general de este vínculo con el otro, esa solicitud puede desplegarse de dos formas básicas: sustitutivo-alienante o anticipativo-liberadora. Dicho de una manera tosca, hay solicitud positiva y negativa. La solicitud puesta en el contexto de nuestra reflexión nos indica que hay vínculos saludables y vínculos enfermizos. Deliberadamente simplificamos el modo de ser de este vínculo, que sin duda admite no solo matices diversos, sino también efectuaciones dialécticas en algunos casos, ambivalentes en otros. Aun así, podemos considerar algo que se ha hecho patente para todos en la situación actual de la pandemia, a saber, que ha implicado un despliegue inédito de una aptitud característica de una sociedad saludable, que podemos comprender como una forma eminente de solicitud anticipativo-liberadora: la solidaridad.

Expresemos esta idea de otro modo: si en el contexto remisional inmediato el SARS-Cov-2 adquiere el sentido de vector perjudicial, por otra parte, el temor ante el virus conlleva, de manera derivada a nivel del mundo compartido, un velar por la vida del otro, de tal modo que el contexto respeccional del virus se transforma de patógeno en mutualístico. La paradoja de esta situación es que siendo suscitada por el temple anímico del miedo, en la que el mundo de la pandemia es abierto como nocivo y amenazante, al mismo tiempo nos dispone a velar por el otro de tal modo que el carácter nocivo comienza a oscilar entre el sí y el no, y en el contexto de la sociedad puede llegar incluso a mostrarse como su contrario. Esta oscilación entre el sí y el no caracteriza, por demás, muchas tentativas de reflexión en torno a la situación actual, que emergen desde diversos ámbitos de la vida 
espiritual de nuestro tiempo. La oscilación entre el sí y el no cobra en ellas la forma de una incertidumbre acerca de si la pandemia podrá traernos algo bueno como sociedad. Sí y no se debaten, y en medio de las tendencias extremas catastrofistas o apologéticas se sitúa un conjunto de tendencias interpretativas moderadas que ven, por un lado, el incremento en los índices de vigilancia y el refinamiento de los aparatos de control del Estado como efecto patógeno derivado; y, de otro, y en relación directa con este, la ampliación de la cobertura estatal en servicios de primera necesidad como salud, alimentación, servicios públicos, etcétera, como efecto benéfico que incrementa la aptitud de la sociedad.

Aunque desde un punto de vista estrictamente biológico no pueda afirmarse que el coronavirus es un virus mutualístico, o que su acción pueda entenderse como una especie de mutualismo, si adoptamos otra perspectiva y nos situamos en un contexto diferente, más amplio, podremos reconocer cierto mutualismo entre el virus y el humano en las condiciones de vida actuales y futuras. En particular, nos lleva a pensar que la entidad virus comporta un cierto carácter paradigmático, o cuando menos incita a cuestionar la comprensión de la vida en el orden biológico como caracterizada por la independencia o la autonomía y que la vida, no definiéndose ya de este modo unívoco en el plano biológico, no puede hacerlo tampoco en la esfera existencial. La vida es esencialmente dependiente y heterónoma, y el sentido ético y positivo de la heteronomía existencial puede ser el de la solidaridad. La solidaridad que emerge en la relación mutualística derivada no se confunde con el asistencialismo o la compasión (aunque puedan estar presentes), y no lo hace porque el mutualismo supone una participación conjunta y recíproca del todo y la parte en el cuidado de la coexistencia. La función mutualística derivada de la acción patógena del virus impone un régimen de reciprocidad en el cuidado de la coexistencia, por ejemplo, en el orden de la salud a escala social, que refuerza el sentido de la experiencia de la solidaridad. 


\section{Solidaridad y primacía de la coexistencia}

Hemos tomado como hilo conductor para esta reflexión acerca del mundo de la pandemia al temple anímico del miedo. Dentro del proyecto filosófico de Heidegger la cuestión de los temples anímicos tiene un lugar muy destacado. El temple anímico constituye un modo básico de ser del hombre que le procura una apertura originaria al mundo y es por ello condición de posibilidad de la captación del ente como ente. El miedo, como hemos visto, es uno de estos temples anímicos, y quizás uno sin el cual la vida humana no sería posible. El miedo, visto a partir de la metabolé que acabamos de describir, posibilita y es responsable del despliegue o la actualización del coestar como coexistencia solidaria en el mundo de la pandemia.

Con todo, quienes tienen alguna familiaridad con la fenomenología de Heidegger pueden sentir un poco ajeno este énfasis que hemos puesto en el temple anímico del miedo. Y es que aun reconociendo que se trata del temple anímico que abre la situación de la pandemia, no deja de notarse la ausencia de un temple anímico que en el conjunto de la ontología fundamental de Heidegger tiene un lugar de privilegio. Me refiero al temple anímico de la angustia. La angustia es el temple anímico fundamental del proyecto de la ontología de la existencia humana por una razón metodológica básica: su capacidad de abrir nuestro ser es incomparablemente mayor que la del miedo. ¿Por qué no partir entonces de la angustia? Respondemos: por una razón fenomenológica elemental. Ateniéndonos a los fenómenos, yendo a las cosas mismas, resulta obligatorio partir del miedo. Es innegable que el virus da miedo y que el miedo es el temple anímico a partir del cual se nos abre el mundo actual de la pandemia con su potencial riqueza existencial y su actual pobreza respeccional. El SARS-Cov-2 da miedo, no angustia.

Entre miedo y angustia se da una diferencia fenomenológica importante: en el primer caso un ente determinado que se aproxima en el mundo es identificado como lo temible, mientras que no podemos situar un ente que tiene este modo de ser para el temple de la angustia. Heidegger recuerda que a la angustia se la relaciona con la nada (1998, pp. 206-213). Algo oprime y nos corta el aliento, pero en el fondo no es nada. Cuando pasa decimos "no era nada". Pero 
esa nada no es algo simplemente negativo. Lo que nos angustia es "nada" en el sentido de nada entitativo, nada que sea un ente dentro del mundo. La angustia nos aísla existencialmente apartándonos de los entes. Nada queda a lo que aferrarse o en lo que esconderse. La nada que angustia es el mundo mismo y con el mundo nuestra existencia como poder estar en el mundo. La angustia nos pone de manera directa y aislada ante nuestro ser como poder-ser. La angustia sería, según esto, un pathos del ser, mientras que diríamos que el miedo es un pathos del ente, en el sentido de aquello de donde proceden y a lo que al mismo tiempo abren uno u otro. Hemos hecho bien, entonces, en poner nuestra reflexión en el orden del pathos del miedo, pues es en el orden del ente, a distintos niveles, que reconocemos la incidencia del virus en nuestra existencia. En el pathos del miedo, y a partir de él, se nos muestran las remisiones de virus - enfermedad - hospitalización - medicina - cuidado intensivo - control - distanciamiento físico - confinamiento, como totalidad respeccional articulada a dos sentidos básicos y opuestos: la infección como aproximación del virus desde el mundo circundante a través del contacto o del contagio y la desinfección aunada al distanciamiento del mundo y el repliegue en el confinamiento como medio para impedir esa aproximación. Constatamos a partir de estos dos sentidos básicos y opuestos lo que ocurre con el ente y lo que nos amenaza a nosotros desde el mundo de la pandemia. Pero ¿qué pasa con nuestro ser? ¿Será posible que el temple anímico del miedo, pese a su limitado alcance ontológico, nos provea, con todo, un modo de acceso a un orden similar a la capacidad de apertura que tiene la angustia? Fenoménicamente constatamos que el miedo es el temple anímico que gobierna el descubrimiento actual del mundo de la pandemia. Sería quizás forzado buscar en el miedo mismo un temple anímico anterior, como la angustia, o incluso intentar suscitarla por medios dialécticos con el fin de hacerla ingresar en la situación actual. Por otra parte, como advierte Heidegger, "es oscura la conexión ontológica de la angustia con el miedo", tanto que incluso se tiende a confundirlos. ¿Será posible acaso que en nuestro análisis hayamos presentido ya, al considerar el temple del miedo, algo del orden de la angustia? Quisiera concluir señalando dos elementos que apuntan en 
esta dirección y que quizás nos pongan sobre la pista de la respuesta a la pregunta planteada en última instancia acerca de nuestro ser.

Volvamos al temple de la angustia, intentando determinar un poco mejor su estructura. La fenomenología del pathos de la angustia sitúa a este temple anímico como un temple fundamental de nuestro ser en la medida en que lo abre de manera propia, es decir, a partir de sí mismo y no a partir del mundo desde el que usualmente nos comprendemos como si se tratara de una especie de espejo. La angustia puede eso, tiene ese poder de apertura, y lo tiene antes que todo proyecto hermenéutico sobre nuestro ser, por las siguientes razones: en la angustia la significatividad del mundo se viene abajo, y con ello la estructura de remisión queda suspendida. Nuestros proyectos vitales no encuentran manera de referirse y desplegarse en los entes intramundanos, quedando remitida nuestra existencia a su desnudo estar-en-el-mundo. En la angustia se cortan, por decirlo así, las posibles direcciones de huida de sí hacia el ente intramundano. En última instancia, nuestro ser queda remitido en la angustia a sí mismo y a la simplicidad de su estar-en-el-mundo. Esta situación puede designarse como aislamiento existencial radical. El miedo, por su parte, hemos visto que conduce también al aislamiento, pero no al aislamiento existencial sino al aislamiento óntico (el distanciamiento físico, por ejemplo). De otra parte, en el miedo ante el virus el mundo se empobrece en su significatividad, y el contexto remisional queda orientado por dos vectores básicos: el vector del posible contagio y el vector del posible bloqueo del contagio, que hemos caracterizado con las expresiones "infección" y "desinfección". En cierto modo el mundo se convierte en un sistema binario, su significación no desaparece, pero queda reducida a esta expresión mínima. El ser humano aislado ónticamente y desprovisto de la riqueza significativa del mundo queda remitido a sí mismo de un modo comparable al procurado por la angustia, y esto incluso a tal punto que el temple anímico puede hacerse indiscernible, lo que agudiza la proximidad entre miedo y angustia. Nuestra existencia, en esta situación, accede, sin embargo, y justamente por esta vía, a una experiencia de la auténtica solicitud que hemos denominado solidaridad, y al hacerlo descubre, quizás de modo más agudo, que su 
estar-en-mundo es al mismo tiempo co-estar.

En este punto, la metabolé del sentido del virus, es decir, el despliegue del sentido mutualístico derivado, más que ser la causa, se nos muestra ahora como un modo óntico determinado de experiencia de nuestro ser no contingente, abierto por la aproximación del miedo a la angustia. Nos posibilita de esta manera una experiencia no cadente de nuestro estar-en-el-mundo como reconocimiento fáctico de nuestro ser y de lo que pasa con nuestro ser. Al mostrar de este modo la proximidad entre miedo y angustia, en principio desde un punto de vista formal, advertimos al mismo tiempo que si bien el aislamiento constituye un elemento característico compartido por la situación abierta en estos temples anímicos, el aislamiento óntico que nos distancia espacialmente del otro conlleva una máxima aproximación existencial al otro, haciéndonos comprender algo que va en una dirección que es casi contraria a la esbozada por Heidegger en la analítica existencial. En efecto, el filósofo alemán ve la angustia como aquel temple anímico en el que "[e]l 'mundo' ya no puede ofrecer nada, ni tampoco la coexistencia de los otros" (Heidegger, 1998, p. 210); mientras que nosotros vemos en esta especie de punto límite en el que el miedo adquiere una dimensión existencial -que parecería ser privativa de la angustia- una manera distinta de comprender nuestro estar-en-el-mundo, como indiscernible del ser-con-otros, llevándonos por esta vía a poner en cuestión este elemento de la analítica heideggeriana y a destacar el co-estar como esencialmente vinculado al ser-sí-mismo.

Creemos alcanzar de esta manera una especie de presupuesto ontológico no cuestionado, y que puede y debe serlo. La analítica de la vida, y la analítica de la vida humana en particular, ha partido de una pre-comprensión de su ser afincada en la idea de autonomía: "El Dasein es propiamente él mismo en el aislamiento originario de la callada resolución dispuesta a la angustia" (Heidegger, 1998, p. 340). Esa autonomía es en el fondo cuestionable. No tenemos ahora ni el espacio ni el tiempo para desarrollar convenientemente este aspecto de nuestra reflexión, pero quisiera indicar cuando menos que en esta definición existencial de la vida humana -o Daseinparece prevalecer de modo subrepticio el orden de la sustancia, 
pese al cuidado de Heidegger por cuestionar este presupuesto de la metafísica como ruinoso para la comprensión de la vida humana. Esto puede apreciarse de manera directa si nos remitimos a una de las primeras definiciones de sustancia (ousía) que nos ha legado Aristóteles en su Metafísica: "[L]o que siendo algo individual es también capaz de existencia separada” (v, 1017b). Esta idea está de tal manera adherida al ADN de nuestra existencia histórica que, ya en el siglo XVII, Descartes (Principios I, 51) propuso que "por substancia sólo cabe entender una cosa que existe de tal manera, que no necesita de ninguna otra para existir" (Descartes, 1989, p. 54).

Por nuestra parte, y siguiendo la vía que abre el temple anímico del miedo proclive a la angustia, sostenemos que el descubrimiento de la vida no podría ir en la dirección de un aislamiento del ser sino de la exhibición de su modo propio de dependencia. El temple de la angustia en la analítica existencial de Heidegger es la piedra de toque de este problema, pues, en definitiva, nos lleva a preguntarnos si un temple anímico que aísla radicalmente al hombre puede conducir a un descubrimiento de su ser propio, o solo conduce a otro modo impropio de ser, el modo impropio de la independencia. Algunos planteamientos de la biología actual como aquellos a los que hemos hecho referencia resultan en cierto modo congruentes con el planteamiento existencial, y por ello pueden remitirse también al cuestionamiento de este presupuesto básico de la analítica existencial, de modo que sea posible con ello alcanzar una situación más amplia y más ajustada a las cosas mismas en lo que concierne a nuestra existencia en órdenes en apariencia inconmensurables, como el óntico-biológico y el ontológico-existencial. Al pensar en esto se nos revela que la mayor proximidad con el otro en sentido ontológico parece alcanzarse en medio de la mayor distancia óntica, en el distanciamiento físico que la pandemia nos impone como forma de vida actual, y que en ella la mayor distancia óntica con el otro es también, como máxima proximidad ontológica con el otro, la mayor proximidad del ser humano consigo mismo en cuanto que su ser es esencialmente co-estar. 
De esta manera la distancia se convierte en aquello que mejor nos permite apreciar la cercanía del otro en la solidaridad, y a esta, a su vez, como sentido existencial originario de la proximidad. El más próximo, el prójimo en este sentido es aquel que se comporta a partir de la solidaridad, es decir, a partir de una forma del cuidado abierta no por la angustia sino por el velar por el otro que emerge del temple anímico del miedo en la época de la pandemia.

\section{Conclusiones}

Nuestro recorrido, que ha estado orientado en un primer momento por un estudio del relato de Tucídides sobre la peste en Atenas, y en un segundo momento por un análisis del sentido fenomenológico-hermenéutico del virus responsable de la CoviD-19, nos permite reconocer cierta solidaridad en la experiencia de la enfermedad y en el modo como el temple anímico del miedo define los lazos de coexistencia.

Un primer índice de esta solidaridad lo hemos situado en aquello que hemos definido como el talante fenomenológico del relato del historiador ateniense, el cual recogemos en el lenguaje mismo en el que habla esta experiencia, y en un giro particular de la lengua griega, que privilegia, incluso desde Homero mismo, tal como hemos querido presentarlo, el mostrarse mismo, el acaecer, el presentarse de la enfermedad, que al mismo tiempo irrumpe en el ámbito vital del pueblo griego, como una especie de enemigo invasor, y en el ánimo de los atenienses.

Este carácter fenomenológico de la descripción de Tucídides coincide con un planteamiento característico de la disciplina fenomenológica, y que consiste en poner entre paréntesis las causas y la procedencia del fenómeno, lo que podríamos decir que incumbe más al campo de la metafísica. Tucídides deja esto de lado, como bien lo expresa en su relato, y se ocupa de exponer el modo como la peste irrumpe en Atenas, embarga a los atenienses y, en particular, cómo altera su ánimo, lo cual conlleva, a su vez, una modificación sustancial de sus modos de relación, o de los lazos de coexistencia. 
En este sentido, la fenomenología de la enfermedad se muestra ante todo en los aspectos del mundo propio, en aquello que con Antonio Hermosa hemos reconocido como el "imperialismo somático" de la enfermedad, así como en las alteraciones del estado de ánimo de los atenienses, descubriendo de este modo, por un lado, las consecuencias psico-somáticas de la peste y, por el otro, en el ámbito del mundo compartido, las alteraciones de la moral que conlleva el ataque de la enfermedad. Las consecuencias de la peste irradian desde el mundo propio hacia el mundo compartido, contaminando la moral de la polis, y desde el mundo compartido hacia el mundo propio, atacando el cuerpo y el alma de los atenienses. Este camino de ida y vuelta nos parece que es descrito de modo magistral por Tucídides, y siguiendo estas líneas de análisis nos sugiere también un camino para nuestra indagación de la peste contemporánea, de la pandemia ocasionada por el SARS-Cov-2.

Dentro de esta fenomenología hemos destacado algunos aspectos presentes en la descripción de Tucídides como, por ejemplo, la temporalidad de la acción de la enfermedad, temporalidad que remite a una especie de aceleración, de cambio repentino en la fortuna de los atenienses, que en parte resulta asociada a los cambios no solo en el estado de ánimo, sino en la moral pública. Estos cambios repentinos, como hemos indicado, impiden a los atenienses "sufrir penalidad por un fin considerado noble". Inhibida esta capacidad, queda abierta la puerta, y abierta podríamos decir por la enfermedad, a la ruina moral del pueblo.

Esta descripción de los efectos de la peste desemboca en el temple anímico del miedo, el cual articula de un modo más profundo el acaecer de la enfermedad. Hemos mostrado que el miedo en exceso o en defecto es el responsable de la ruina moral de la polis asediada por la peste. Si es en exceso, mueren abandonados los habitantes de la ciudad, por no visitarse los unos a los otros; si es por defecto, no funciona como freno a la acción innoble. Este contraste en la función del miedo nos lleva a preguntarnos con más ahínco por su operación en la situación de pandemia actual.

En este punto nuestra reflexión efectúa un giro hacia el estudio de la pandemia actual, y se interroga por el modo como el miedo 
funciona en ella, pregunta que es abordada desde la analítica existencial del miedo. El punto de partida es el siguiente: si los temples anímicos tienen una función determinante en la apertura del Dasein al mundo, ¿de qué modo nos abre el mundo el temple anímico del miedo suscitado por el virus causante de la Covid-19? Esta pregunta sitúa el énfasis de nuestro análisis en un temple anímico que si bien fue estudiado por Heidegger en su analítica existencial, no tuvo el mismo rango que la angustia. Consideramos que siempre será posible remitir a la angustia algunas experiencias destacadas de la situación actual de pandemia. Hay angustia en el confinamiento, en la incertidumbre, en el no saber a qué atenerse. La pandemia de la Covid-19 no solo ha ocasionado miedo; sin ninguna duda, la angustia ha sido también un temple anímico presente y ha extendido su radio de acción, su sintomatología, su atenazador poder durante los dos primeros años de la pandemia. Con todo, hemos querido desplazar el acento de nuestro análisis sobre el temple del miedo con el fin de destacar aspectos que, por lo general, no son tratados dentro de los estudios heideggerianos, que relegan el miedo a temple anímico inauténtico o impropio, de segundo rango, angustia cadente, como diría Heidegger.

En el último segmento de nuestro análisis, y en contra de esta tendencia, hemos querido mostrar, por el contrario, que el temple anímico del miedo puede ser responsable de una peculiar recuperación de la coexistencia, propiamente experimentada, a partir de los lazos de solidaridad, y que en ello el miedo muestra una versión contrarruinante del temple anímico, que dispone al ser humano en sociedad a formas de solicitud o asistencia positivas. En tal sentido, y en contra de lo narrado por Tucídides, podemos describir y descubrir, mediante el análisis del temple anímico del miedo, un efecto virtuoso, una recuperación de la vida comunitaria, moralmente encarecida aun en medio de una situación en extremo penosa $\mathbb{C}$ 


\section{Referencias}

Aristóteles (1994). Retórica [Rh.] (Intr., trad. y notas de Q. Racionero). Madrid.

Aristóteles (2018). Metafísica [Metaph.] (Intr., trad. y notas de T. Calvo Martínez). Gredos.

Descartes, R. (1989). Sobre los principios de la filosofía (E. López y M. Graña, Trads.). Gredos.

Heidegger, M. (1998). Ser y tiempo (Trad., pról. y notas de J. E. Rivera Cruchaga). Editorial Universitaria.

Hermosa Andújar, A. (2016). ¿Civilización o barbarie? La peste de Atenas o el retorno de la historia a la naturaleza (ensayo sobre Tucídides). Bajo Palabra, (12), 113-126. https://doi.org/10.15366/bp2016.12.009

Homero (2012). Ilíada (Ed. bilingüe de F. Javier Pérez). Abada Editores.

Lwoff, A. (1957). The concept of virus. Microbiology, 17(2), 239-253. https:// doi.org/10.1099/00221287-17-2-239

Nietzsche, F. (1972). Así habló Zaratustra (A. Sánchez Pascual, Trad.). Alianza.

Pradeu, T. (2016). Mutualistic viruses and the heteronomy of life. Studies in History and Philosophy of Science Part C: Studies in History and Philosophy of Biological and Biomedical Sciences, 59, 80-88. https://doi. org/10.1016/j.shpsc.2016.02.007

Simpson, D. (2019). States of Terror: History, Theory, Literature. The University of Chicago Press.

Thucydide [Th.]. (1973). La guerre du Péloponnèse (J. de Romilly, Trad.). Les Belles Lettres.

Tucídides [Th.]. (2019). Historia de la guerra del Peloponeso [Hist.] (J. J. Torres Esbarranch, Trad.). Gredos.

Zaborowski, R. (2002). La crainte et le courage dans L'Iliade et L'Odisee. Stakroos. 